\title{
SOBRE EL HORACIANISMO DE FRANCISCO DE RIOJA
}

RAFAel Herrera Montero

me peritus discet Hiber.

(Hor. Carm. II 20)

\section{PRESENTACIÓN}

La impronta de Horacio en nuestras letras clásicas es una de las constantes más señaladas en lo que se refiere a la Tradición Clásica en España. Sin embargo, a la llamada escuela sevillana se le ha negado tradicionalmente tal filiación; categoricamente lo exponía Menéndez Pelayo en su incomparable Horacio en España: "La escuela sevillana dió en su primer período notables humanistas, traductores de Horacio y poetas en lengua latina a imitación suya, pero escasísimos líricos horacianos en lengua vulgar» ${ }^{1}$.

Pero esta afirmación está motivada por la concepción que Menéndez Pelayo tenía del horacianismo, una forma de imitación muy concreta e indudablemente relacionada con la escuela salmantina y el modelo de Fray Luis de León; por ello, es lógico que no halle mucho de este horacianismo en los sevillanos. Sin embargo, un estudio a fondo de la obra de los poetas de ese círculo, a partir del verdadero Horacio, no de una forma de horacianismo preconcebida, sino

1 Cito por Bíbliografia Hispano-Latina Clásica, t. VI, Santander, CSIC, 1951, p.317. 
desde el texto de las Odas (nos centramos, claro, en el Horacio lírico), puede revelar muchos puntos de contacto y diferentes formas de imitación, evocación, recuerdo, ecos, reminiscencias y todas esas formas de pervivencia que tanto nos interesan en la Tradición Clásica.

Vamos a centrarnos, en esta ocasión, en un autor que, siendo claramente sevillano $^{2}$, sí revela un horacianismo consciente, hasta el punto de que Menéndez Pelayo le dedica algunos comentarios al respecto, al calificar a Rioja de «un admirable poeta, y poeta con frecuencia horaciano», y señala algunos lugares ilustrativos. Pero aparte de las escuetas referencias del polígrafo ${ }^{3}$, podemos detectar otros muchos puntos de imitación en ese sentido más amplio que proponemos.

RIOJA Y los CLÁsICOS. SU CONOCIMIENTO DE HORACIO

Antes de señalar fuentes o posibles imitaciones en un autor parece de rigor constatar, si hay datos que lo posibiliten, su conocimiento e implicación con el modelo; una precacución metodológica que no siempre se toma y que puede inducir a errores.

Pero desde luego en el caso de Rioja hay testimonios suficientes de su erudición, así que no sería demasía suponerle a priori un buen conocimiento del venusino. Destacaremos, no obstante, algunos datos ilustrativos.

Un primer testimonio sobre su educación nos ofrece el propio poeta, en un memorial dirigido al rey de hacia 1617 y que se conserva en el ms. 5781 de la Biblioteca nacional de Madrid, fol. $129^{4}$, donde declara:

«el licenciado françisco de rrioja, clérigo presbítero, natural de la ciudad de Sevilla i graduado en sagrada teolojía por aquella universidad, dize que a estudiado en su facultad con el cuidado i diligencia de que vuestra magestad se podrá mandar informar, aviendo aprendido las lenguas latina, griega y hebrea, i trabajado en ellas con mucho fructo, de que ha nacido el tener hechas notas i particulares estudios en los

2 El caso de Francisco de MEdRano no sería relevante porque es, en sus presupuestos, un autor mucho más salmantino que sevillano.

3 En op. cit. p. 330-31.

4 Tomamos el dato de Francisco de Rioja. Poesía. ed. de Begoña López Bueno, Madrid, Cátedra, 1984, p. 15 . 
más libros de la escritura i en los santos i concilios antiguos, i algunos tratados particulares en diferentes materias, con aprobación i estimación de los ombres doctos».

Si la naturaleza del documento, destinado a conseguir una capellanía, y el estar escrito por el propio interesado, pudieran hacer dudar de su veracidad, basta recordar algunas de sus obras y «anotaciones» para constatar su erudición con respecto a los clásicos. Aparte de su intensa relación con la llamada Academia sevillana ${ }^{5}$, donde debía compartir las lecturas y conocimientos del maestro Mal Lara ${ }^{6}$.

Hay constancia de varios trabajos suyos de erudición, como el prólogo a la edición de Versos de Fernando de Herrera de $1619^{7}$, y los recogidos en Tratados de erudición de varios autores (ms. 1713 BNM). En el primero de los trabajos, sobre el que nos detendremos luego para ilustrar su concepto de imitación, defiende el clacisismo de Herrera con referencia a varios autores clásicos, en citas directas o indirectas, muchas de ellas tomadas, con toda probabilidad, de manuales de clacisismo de la época, como el de Hermógenes o el de Rabisisus Textor, etc. Pero indudablemente, fuera cual fuera su procedencia, formaba parte de su caudal literario; baste con citar la nómina de autores que cita en su breve prólogo para dar una idea de la amplitud de sus lecturas: Cameleón, Esquilo, Laberio, Virgilio, Escalígero, Manlio, Anacreonte, Aristóteles, Quinto Catulo, Platón, Calímaco, Filetas, Hermesianacte de Colofón, Teognis, Solón, Tirteo, Mimnermo, Alejandro Etolo, Propercio, Tibulo y Albinovano son, por orden de aparición, los protagonistas de esa breve representación de su saber. ¿Es poco?

Veamos un ejemplo del uso que hace de esas autoridades; señala en el prólogo, para defender un supuesto descuido de Herrera, un lugar de Virgilio:

"Tendrá alguno a inorancia, aver llamado "Indo" al que beue el Nilo, cuando dige en la elegía a don Pedro de Cúniga,

Do el Indo beve el Nilo i se colora, será con más estima venerado.

5 Cf. A. LAsso de la Vega y ARgólles, Historia y juicio critico de la escuela poética sevillana de los siglos XVI y XVII, Madrid, 1871.

6 Para la complejidad de su erudición, cf. I. OsUNA, Las traducciones de autores clásicos en la Filosofía Vulgar de JUAN DE MAL LARA, (tesina, aun inédita), Universidad de Córdoba, 1994.

7 Puede leerse en FERNANDO de HERRERA, Poesía castellana original completa. ed. CRISTóbal Cuevas, Madrid, Cátedra, 1985, pp. 479-486. 
I es imitación de Virgilio en el 4 de las Geórgicas, que dijo.

Quaeque pharetratae vicinia Persidis urget,

Et viridem Aegyptum nigra foecundat arena,

Et diversa ruens septem discurrit in ora

Vsque coloratis amnis devexus ab Indis.

I no sólo él, sino alguno de los escritores antiguos, como nota Iosefo Escaligero en Manilio.» ${ }^{8}$.

Vemos cuán fino anduvo para tener a mano un lugar de la máxima autoridad, Virgilio, que avala la alusión de geografía antigua, dominio tan proclive a confusiones que hoy nos parecen de menor importancia. Hay que matizar, no obstante, el empleo: el texto que ofrece Rioja difiere de la edición hoy canónica. En efecto, el orden de los versos aparece cambiado en la edición oxoniense de Virgilio ${ }^{9}$, desplazando el v. 291 tras el 293, es decir,

Et uiridem Aegyptum nigra fecundat harena

tras

usque coloratis amnis deuexus ab Indis

tal como aparece en el Vat. Lat. 3867, disposición de versos que adopta Mynors porque aaliter positis, iterato et languet sententia». Pero hay que tener en cuenta que Rioja se ciñe al texto habitual en su época y lo que aquí nos interesa es observar su prontitud de recursos eruditos, aunque estos vengan mediatizados por manuales como los citados antes o el aquí recordado Poetices libri septem de Escalígero.

Para no extendernos más sobre este punto, presentaremos un dato inédito que reitera la fineza filológica de Rioja y su dominio de la erudición en la línea del ejemplo anterior, al tiempo que aclaramos algún error de atribución:

En la bibliografía que Cristóbal Cuevas ofrece en su edición de Herrera ${ }^{10}$, dice que el citado ms. 1713 BNM, en el f. 34, «incluye un poema latino de Herrera al conde de Gelves: Dum tu nubiferos tractus et inhospita tesqua». Desgraciadamente para los amantes de la poesía neolatina no incluye tal poema,

8 En la ed. de Cuevas, p. 480. El poema de HerRera a que hace referencia es la Elegia VI de Versos II, vv. 166-67; el lugar de Virgilio, Georg. IV 289-292.

9 P. VERGIL MARONIS OPERA, recognouit breuique adnotatione critica instruxit R.A.B. Mynors, Oxford 1969, p. 92.

10 Op. cit., p. 105. 
sino solo los dos primeros versos que el autor del documento, Rioja, cita para defenderlos de alguna crítica. Por ser el dato inédito y de interés para el asunto que tratamos, reproducimos el texto completo:

"de Francisco de Rioja

a Don Alvaro de Portugal conde de Gelves hizo Fernando de Herrera unos versos que començavan assi:

Dum tu nubiferos tractus, et inhospita tesqua, preruptos montes, et depressas convalles, 2

ó

que censuro assi el licenciado Rodrigo Caro

el 2 verso del poema de Fernando de Herrera, es spondaico. pero no observa la ley de los tales versos, que el 4 pie a de ser un dactilo.

en cuya defensa respondio desta manera Francisco de Rioja

engañóse en esto que dize el señor Rodrigo Caro, porque hizo Fernando de Herrera lo que Virgilio en el 3 de las Georgicas, que haze tambien en verso espondaico el 4 pie espondeo-

saxa per scopulos et depresus convalles

i esto lo haze Catulo algunas vezes, en su Argonauta, de manera que bien hizo Herrera i con buensa imitación».

Está fechado el 22 de junio de 1619, y es prueba de su habilidad, primero por disertar sobre disciplina tan descuidada habitualmente como la métrica latina, segundo por aducir testimonios de autoridades que implican un buen manejo de la literatura clásica.

En este contexto, pues, es donde hay que insertar su conocimiento de Horacio. Indudable, cuando era este el modelo especialmente querido en la escuela que frecuentaba. El razonamiento es claro:

1) Horacio es el modelo de poeta lírico latino por excelencia. El propio Herrera, teórico de la escuela, decía que «...éste fue Horacio, casi sólo digno de ser leído entre sus líricos, y el más elaborado de todos los poetas griegos y latinos. Felicísimamente osado en las voces, lleno de gracia y jocunda invención y novedad, y de purísima lengua y variedad de figuras, y maravilloso espíritu y viveza» ${ }^{11}$, consideración tópica ya desde Quintiliano ${ }^{12}$.

11 En sus Anotaciones a Garcilaso de 1580. Es la anotación H-187 en la ed. de A, GALLEGo MORELL, GARCILASO DE LA VEGa y sus comentaristas, Madrid, Gredos, 1972, por la que citaremos en adelante.

12 Inst. Orat. X 1, 96. «At lyricorum idem Horatius fere solus legi dignus, nam et insurgit aliquando et plenus et iucunditatis et gratiae et uarius figuris et uerbis felicissime audax*. 
2) La escuela sevillana destaca en su afán de imitación de los modelos clásicos, en los que hay que basarse. También el legislador de la Academia decía: «Yo, si deseara nombre en estos estudios [...] enderezara el camino en seguimiento de los mejores antiguos» 13 .

3) El poeta lírico ha de tener por modelo a Horacio, parece una conclusión evidente.

Pero ya decíamos que el horacianismo de la escuela sevillana es sui generis. Veamos qué entiende Rioja por imitación.

EL CONCEPTO DE IMITACIÓN EN RIOJA

De nuevo recurrimos al prólogo de Versos de Fernando de Herrera, porque allí nos ofrece Rioja un testimonio inapreciable de su concepto de imitación. En efecto, señala varios lugares de Herrera que él considera imitados de autores antiguos (un primer ejemplo sería el que antes comentábamos sobre la geografía). Por tanto, es una prueba indiscutible de lo que él considera imitación.

Así, señala un epigrama de Quinto Catulo, citado por Cicerón (De natura deorum I 79) y que de ahí pasó a los manuales, como fuente del soneto LII del libro II de Versos. El texto modelo es el siguiente:

Constiteram, exorientem Auroram forte salutans,

quom subito, a laeva, Roscius exoritur;

Pace mihi liceat, coelestes, dicere vestra:

Mortalis, visust pulchrior esse Deo.

y dice que Herrera trató su sentencia así:

Cuando sale mi Luz, i en Oriente

Desmaya el puro ardor; ¡ $\hat{o}$ vos, d'el cielo

Vagas lumbres!, si tanto se consiente,

Digo, con vuestra paz, qu'en mortal velo,

Más que vos, bella apareció i fulgente

Mi Luz, qu'onora el rico Esperio suelo ${ }^{14}$.

13 En com. H-1 de Anotaciones.

14 Todo esto en FERNANDO DE HERRERA, ed. cit., p. 482. 
Igualmente descubre una fuente común a dos composiciones herrerianas:

«Pues el epigrama de Platón, cuio principio es:

O utinam coelum fierem cum sidera cernis,

Mi Stella, ut multis in te oculis tuerer,

¿cómo lo imita en el soneto

¡O fuera yo el Olimpo!, que con buelo?

¿I en la elegía que comiença

A la pequeña luz del breve día?»15.

Ambos casos revelan un concepto muy generoso de la imitación, lejano desde luego de la imitación servil. Se toman ideas y se desarrollan, sin que por eso deje de estar presente y detectable la fuente. Basta comparar los textos modelos con su desarrollo para advertir la libertad en su tratamiento.

Sin embargo, tenemos otro ejemplo de imitación muy al detalle, en el extremo opuesto a lo anterior. Así señala la imitación de un recurso retórico, en este caso de índole métrica, como es el uso de la diéresis. En concreto recuerda el v. 281 de la Georg. I.

\section{Ter sunt conati inponere Pelio Ossam ${ }^{16}$}

como modelo del soneto LVIII de Versos III,

y del LX:

Huyo i vo alexándome, mas cuanto...

D'el golpe i de la carga mal tratado Me alço apena, i a mi antigua guerra.

Conviene recordar que el propio Herrera había citado ${ }^{17}$ ese mismo verso de Virgilio como modelo de diéresis para otros varios versos suyos ya en 1580 (fecha de las Anotaciones). Lo que hace aquí Rioja es aplicarlo a nuevos versos con ese procedimiento incluidos en la edición que prologa.

Cita otros ejemplos de esta imitación de detalle, en aspectos retóricos como «la trasposición de las palabras», o sea, el hipérbaton (con modelo en En.,

15 El texto de Platón lo toma del epigrama 669 de la Serie funeraria de la Antología palatina, según el ms. Palatino de Jacobs (así lo cita CuEVAS). El original griego, no obstante, está en A.P. 7669.

16 El verso es proverbial como ejemplo de diéresis, procedimiento antiguo que pone MYNORS en paralelo con Od. II 596 ( en Vergil . Georgics, edited with a commentary by R. A . B. MYNORS, Oxford 1990, ad loc.).

17 En Anotaciones, H-13. 
V 481) y los recursos métricos finos, como los que Ferguson llama «versificación imitativa» ${ }^{18}$ : «...por la significación, quiso que sirviesen los números a la sentencia. Nuestro autor hizo lo mismo en la Gigantomaquia:

Vn profundo murmurio lexos suena

Qu'el hondo Ponto, en tomo, todo atruena» ${ }^{19}$.

Vemos, desde luego, hilar muy fino, y que la imitación es para Rioja algo extremadamente sutil. Esto nos autoriza a señalar lugares donde la imitación se perciba de esta manera. Cuando hay ecos verbales claros, la afirmación es sólida, pero ésos están en mayor medida detectados. Insistiremos, pues, en estos otros, indudablemente de más difícil constatación, por lo que habrá que proceder con prudencia en su localización y cautela en la atribución.

HORACIO EN RIOJA

\section{En lo formal}

Por esta precaución metodológica tal vez fuera mejor pasar por alto algunos de esos casos de detalle, de siempre arriesgada filiación por cuanto no se insertan en un contexto claramente identificable, sino que se limitan a un rasgo de estilo a menudo compartido por varios autores antiguos y no privativo de Horacio. Sin embargo, teniendo en cuenta que éste es el modelo lírico, lo hace favorito en algunas ocasiones, como en ciertas formas de hipérbaton, figura que Dámaso Alonso ${ }^{20}$ describía como típicamente horaciana. «Hipérbaton culto, trasplantado directamente del latín» y característico precisamente de Fray Luis y Medrano, pero también compartido por Herrera: «Abunda [el hipérbaton] en Fray Luis y Herrera y, - nótese bien- no pasa, o escasamente, al arte barroco». Algunos de estos se encuentran en Rioja, como

1981

18 W. FERGUSON, La versificación imitativa en FERNANDO DE HERRERA, Londres, Támesis,

19 P. 484 ed. cit.

20 DÁmaso Alonso, Poesía española. Ensayo de límites y metodos estillsticos. Madrid, Gredos, 1957. 
ni otro sitio invidiando ni otro cielo

$(\text { son. } V 4)^{21}$

pura i cándida Ilitia, que luciente

eres del cielo onor...

(son. XX 5-6)

en el órrido ivierno i proceloso

(son. XXI 4)

$Y$ hasta en un cuarteto entero, como en las estrofas de revuelta construcción de Horacio:

Triste pensava yo nunca sobrado sentir tal vez el ardimiento mío, o elasse al Tánais el ivierno frío, o regalasse el sol su curso elado.

(son. VII 5-8)

De hecho, en este ejemplo la imitación formal se da dentro de un contexto horaciano, el motivo ponmi que estudiaremos más adelante. Otro poema con este tópico, reconocido ya como horaciano por Menéndez Pelayo y otros estudiosos y del que también nos ocuparemos luego, termina igualmente con el recurso:

ni de Bóreas la saña impetuosa.

(son. X 14)

Pero aun más que en este recurso, donde no puede caber duda de la raigambre horaciana, es en dos procedimientos que son exclusivos de Horacio, «inventados» por él. Los llamados «callida iunctura» y «morosidad descriptiva». El primero es ya una constante en los estudios de estilística horaciana, desarrollado ampliamente por especialistas como Pierre Grimal ${ }^{22}$ y F. Cupaiuo$10^{23}$. Vicente Cristóbal ${ }^{24}$ lo define como combinación de figuras (oxímoron, aliteraciones e incluso rimas) que aprovechan la libertad del latín para colocar las palabras en lugares destacados ocasionando asociaciones solidarias de alto valor efectista.

21 Citamos siempre por la edición de Begoña López Bueno, francisco de RIoja. Poesía. Madrid, Cátedra, 1984.

22 En Essai sur l'Art Poétique d'Horace, París 1968 y Le lyrisme à Rome, París 1978.

23 A proposito della «callida iunctura oraziana, Nápoles 1942.

24 Horacio. Odas y Epodos. Edición bilinguie de Manuel Fernández-Galiano y V. CrisTÓBAL, Madrid, Cátedra 1990, pp. 40-41. 
Algo de esto percibimos en Rioja, como en su soneto XXI (vv. 1-4):

Este sediento campo, que abundoso de roxa mies contemplo en el estío, vi cubierto de umor luziente y frío en el 6rrido ivierno i proceloso.

Destacamos en cursiva las palabras clave que se oponen y dan a la estrofa una unión cálida, una íntima trabazón a la manera horaciana destacada además por la rima. Si consideramos también el hipérbaton del verso 4 , y el contexto de temática horaciana que luego veremos en este poema, el recurso parece inapelable.

Otro caso similar ofrece el soneto XXIII (vv. 5-8)
¿Inoras, por ventura, cuánto pueda
más estender su luz resplandeciente
la llama que en mi pecho acerbamente
i dulce, el engañoso amor ospeda?

También es una coincidencia de figuras, recurriendo además a la rima, para destacar los contrarios y formar esa sutileza de pensamiento cargada de expresividad. Recordemos de paso cómo el oxímoron que aparece aquí es favorito de Rioja, que ya lo emplea casi con la misma formulación en el soneto I, v. 4:

mi acerba i dulce i clara luz serena.

Un tercer caso donde la expresión se condensa en una estrecha trama de relaciones conceptuales apoyadas por la rima y el paralelismo, vemos en la silva IV:
sábeslo, i la codicia
tu alta razón pervierte;
mira que la codicia
a nadie quita la devida muerte.

Las relaciones entre pares son complejas, por semejanza u oposición, para expresar un pensamiento tan propio de la moral horaciana y -dato incuestionable - en un poema que es traducción - paráfrasis de una de las más famosas odas de Horacio, la II 16 (Otium diuos rogat in patenti).

Para cerrar este capítulo, otro recurso exclusivo de Horacio cuya identifi- 
cación debemos a V. Cristóbal, la morosidad descriptiva ${ }^{25}$. Consiste tal recurso en la desviación, al final de la oda, del hilo argumental, para centrarse en un detalle concreto que se extiende morosamente, hasta el final, como un primer plano cinematográfico que cierra detenidamente la secuencia. V. Cristóbal sitúa bien el procedimiento en muchos lugares de Horacio, e identifica su imitación por parte de Fray Luis. Por nuestra parte, podríamos ofrecer algunos lugares de imitación en Herrera (canción 88 de Poesías varias, elegía VII de Algunas obras, soneto XCV de Versos II, todo en la ed. cit. de Cuevas), así aclimatado a la escuela sevillana; se puede encontrar también en Rioja. Véase este ejemplo de su silva XI, $A$ l jazmin: tras varias reflexiones, se centra en la incidencia de la luz y concluye con ella en la invocación final:

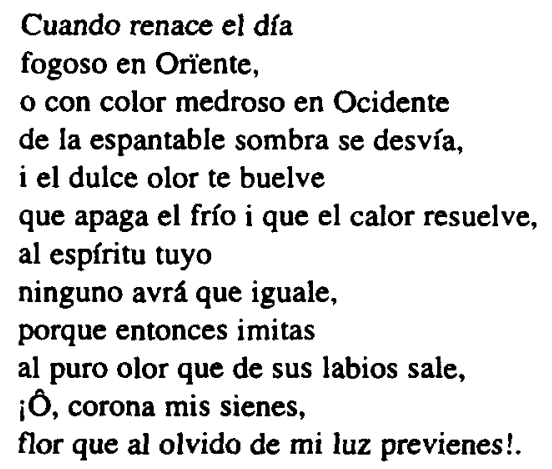

Pero incluso la concisión del soneto permite el recurso, reservando, por ejemplo, los tercetos para la desviación «en fuga», como los de este soneto XLIX:

¡Cómo a ser inmortal, Manlio, caminas!, pues cuando el orbe en pieças dividido, cae con ímpetu orrendo i con ruïdo, intrépido te hieren sus ruinas.

Émulas, Manlio, son de las divinas tus acciones; del número embestido ni passas a sus vozes advertido, ni a sus injurias aun la frente inclinas.

25 «Morosidad descriptiva en las Odas de HORACIO», Retórica y Poética (Ed. J.A. HeRnánDEZ GUERRERO), Cádiz, 1991, pp. 123-136. 
Assí el luziente cerco de la luna, rayando en muda noche el oriente, furioso can latiendo va erizado;

i ella igual i segura i refulgente sube, mal advertida a la importuna voz del can simple, en daño suyo airado.

Los tercetos se extienden, pues, en una comparación que se aleja del tema central que, curiosamente, es horaciano, imitación de la oda III 3 en su primer cuarteto y reformulación del odi profanum vulgus en el segundo, como luego estudiaremos. Curiosa contaminatio de temas horacianos sumando además el horaciano recurso de la morosidad descriptiva.

\section{Temas y motivos horacianos:}

\section{Odi profanum uulgus}

Comencemos por una fórmula tan típicamente horaciana como la que abre sus Odas romanas y que se ha convertido en una de las más célebres características de la poética del venusino. Es aquella del inicio de III 1

Odi prufanum uulgus et arceo;

fauete linguis; carmina non prius

audita Musarum sacerdos

uirginibus puerisque canto.

Ya tópico, ese desprecio del vulgo profano lo recoge Rioja en, por ejemplo, el soneto XXVIII (vv. 9-10):

No temas, pues, del inconstante i ciego vulgo ser habla un poco...

y en el ya citado soneto XLIX en su segundo cuarteto:

...del número embestido

ni passas a sus vozes advertido,

ni a sus injurias aún la frente inclinas. 
en ambos casos, la fórmula horaciana (en el segundo apuntada va por B. López en nota a pie de pág.) se toma no ad pedem litterae, sino recogiendo su sentido para la propia intención del poema.

\section{Pone me/Extremum si biberes}

Otro motivo horaciano que ha tenido larga y prolija fortuna es el que contienen los versos 17 a 24 de la Oda I 22 ,

Pone me pigris ubi nulla campis

arbor aestiua recreatur aura

quod latus mundi nebulae malusque

Iupiter urget;

Pone sub curru nimium propinqui

solis, in terra domibus negata;

dulce ridentem Lalagen amabo,

dulce loquentem.

El motivo, que destaca la constancia del amante aún en las situaciones más adversas, fue adaptado por Petrarca ${ }^{26}$ en sus versos

Ponmi, ove'l Sol occide i fiore, e l'herba,

$O$ dove vince lui'l ghiaccio, e le neve:

Ponmi ove'l carro suo temprato e leve:

Et ove e, chi cel rende o chi cel serba...

con tal éxito que el tópico ha pasado a designarse como «ponmi ove'l sole», no obstante su indudable raigambre horaciana.

Pues bien, en España goza el tópico de inmejorable salud, y ya aparece en Garcilaso en su Elegía II, 175 ss. y en su Canción I, 1 ss., imitación señalada por los comentarios del Brocense y Herrera ${ }^{27}$.

26 Sobre el horacianismo de Petrarca, cf. R. ARGENIO, «Orazio cantato dal Petrarca e dal Poliziano", Revista di Studi Classiel 15, 1967, pp. 331-344; y G. Billanovich, «ll Petrarca e i Classicim, Studi Petrarcheschi VII, 1961, pp. 21-23.

27 Los comentarios del Brocense pueden verse también en la ed. cit. de A. GaLLEGO MORELL, GARCILASO DE LA VEGA... 
El propio Herrera lo utiliza a menudo, además de haber traducido las dos estrofas horacianas en sus Anotaciones. Pues bien, resulta que ese tópico horaciano se mezcla y confunde a menudo con el comienzo de la oda III 10:

\author{
Extremum Tanain si biberes, Lyce, \\ saeuo nupta uiro, me tamen asperas \\ porrectum ante foris obicere incolis \\ plorares Aquilonibus...
}

En realidad Herrera, tal vez para distinguirse de su rival el Brocense, señalaba que éste era el modelo de la Canción I de Garcilaso, aunque lo citaba a través de Sannazaro:

$S$ 'al freddo Tanai, alle cocente arene

di Libia io vò, se dove nasce il sole, o dove il sente in mar strider Atlante...

Recuerdos de ambos lugares en contaminatio ofrece Rioja, recogiendo el tópico, ya altamente codificado, en estos versos que citamos antes a propósito del hipérbaton:

\begin{abstract}
Triste pensava yo nunca sobrado sentir tal vez el ardimiento mío, o elasse el Tánais en ivierno frío, o regalasse el sol su curso elado
\end{abstract} (son. VII 5-8).

También lo encontramos en el soneto $\mathrm{X}$, identificado ya con la Oda III 10 de Horacio por Menéndez Pelayo ${ }^{28}$, y recordado por Begoña López Bueno en nota a pie de su ed. y por V. Cristóbal en la introducción al poema en su edición bilingüe ya citada (p. 267):
Aunque pisaras, Fili, la sedienta arena qu'en la Libia Apolo enciende, sintieras, ¡ai!, que el aquilón me ofende, i del yelo i rigor la pluvia lenta. 


\begin{abstract}
Oye con qué rüido la violenta
furia del viento en el jardín s'estiende,

i que apena aun la puerta se defiende

del soplo qu'en mi daño se acrecienta.
\end{abstract}

Pon la soberbia, o Fili, i blandos ojos

muestra, pues ves en lágrimas bañado

el umbral que adorné de blanda rosa;

que no siempre tu ceño $i$ tus enojos

podré sufrir, ni el mustio ivierno elado,

ni de Bóreas la saña impetuosa.

Señala Chiappini en su edición ${ }^{29}$ que «il tono malizioso di Orazio trova da Rioja la raffigurazione di un amante freddoloso e valetudinario che non sa scherzare, ma e profondamente irritato ${ }^{30}$. Ciertamente, el proceder de Rioja como adaptador es bastante libre, pero esto no es una excepción; las leyes y la concisión del soneto obligan a una reformulación de la materia ${ }^{31}$, aparte de las cualidades poéticas del autor.

Resulta, por ejemplo, curioso el vocativo Fili que sustituye a la Lyce de Horacio. Aunque no es objeto de este estudio el esclarecimiento de los nombres propios de Rioja, resulta interesante detenerse un momento sobre su consideración. Usa nuestro poeta de nombres ficticios de mujeres, con intención más o menos clara y que no debemos confundir con peripecias biográficas; son puramente convencionales, como Lesbia, que aparece en dos ocasiones: el son. XXIV y el LVII. Ambos tienen en común la advocación admirada a una mujer; la consecuencia literaria no puede ser más obvia: el peso de la admiración de Catulo por su Lesbia es proverbial (expresado magníficamente en su poema LI) y no era Rioja ajeno al influjo de Catulo (recordemos que tradujo su poema IV, Phasellus iste... en su soneto XIX Este que ves, ô güesped, vasto pino). Otros nombres convencionales son Clori (utilizado en algún soneto y en sus

29 FRANCISCO DE RIOJA. Studio, testo, traduzione e commento a cura di Gaetano Chiappíni, Università degli Studi di Firenze, Casa editrice D'Anna, 1975, pp. 419-421.

30 Cit. por B. LOPEZ en nota al poema, p. 148.

31 La validez del soneto como forma de adaptación de las odas latinas fue ya reivindicada por Herrera y discutida en la famosa controversia. De la amplia bibliografía destinada a estudiar los cauces métricos para versiones horacianas destacamos las observaciones recogidas en E. DIEZ ECHARRI, Teorias métricas del Siglo de Oro, Madrid, CSIC, 1970, pp. 267-304; e I. OSUNA, «Tendencias métricas en las traducciones de odas clásicas en el Siglo de Oro», II Encuentros Internacionales sobre Poesía del Siglo de Oro. La Oda. Sevilla-Córdoba, 1993, pp. 383-397. 
dos décimas), Tirsi(s), Aglaya y Aglaida. Este último parece relacionarse con Laida, que aparece efectivamente sin variación en la sestina II pero que es variante de Fili en algunos manuscritos. En efecto, tanto para el soneto $\mathrm{X}$ que comentamos como en el XII, la versión del ms. 3888 de la Biblioteca Nacional de Madrid, fols. 213-244, ofrece una primera lectura «Laida» tachada y corregida como «Fili» en todas las ocurrencias de ambos sonetos. Por su parte, el ms. 10195 BNM ofrece «Laida» como lectura única. El nombre de Fili, sin embargo, aparece sin variación en los sonetos L, LI y LV. Dice López Bueno en nota a pie al LI (p. 218) que «Fili es el ejemplo de mujer artera que induce a un amor sentido como trampa por el poeta desde la atalaya de su desengaño». Esto es válido para estas tres apariciones, poemas que podrían formar un ciclo junto con el LIII al que Begoña López remite, aunque éste ofrece el nombre de «Cloe».

Pero el X y el XII son de diferente materia desde luego, y aunque Laida fuera de esa primera redacción corregida por el propio autor, ofrece un nombre más cercano al «Lyce» del original. Sin embargo la corrección no parece sino abundar en el propósito de adaptación y cierto distanciamiento para no caer en la imitación servil. Para ello, recurre a otro nombre frecuente en Horacio, Fili (el venusino lo usa en II 4, 14 y IV 11,3) rechazando el «Lyce» del original que sin embargo emplea en otro lugar, el soneto LVI donde también se refiere a la aspereza de su dama y en adaptación de otro tema horaciano sobre el que volveremos (los motivos marinos).

Pero sobre el prurito de variación poco se puede decir más que señalarlo: Sí nos importan las coincidencias, y en este soneto hay desde luego ecos verbales claros y directos del modelo horaciano, como el «Aquilon» (v. $3=$ Aquilonibus v.4), «Oye con qué rüido» (v.5=audis quo strepitu v.5) o el imperativo «Pon la soberbia» (v.9=Pone superbiam v.9), por destacar sólo algunos de los muchos contactos.

\section{Mitología}

Cambiamos de tercio para pasar al tendido mitológico, lugar común codificado en nuestra poesía del Siglo de Oro, hasta el punto de que muchas de las figuras mitológicas de los versos de Rioja son compartidas por todos los poetas antiguos contemporáneos suyos, y así no hay que buscar la filiación exacta de cada mito que se menciona y buscarle una fuente (que, por otra parte, suele resultar ser las Metamorfosis de Ovidio). Distinto caso es cuando un mito 
aparece con una significación o en un contexto concreto: así, no puede decirse nunca que Apolo o Diana sean tomados de Horacio, pero sí si en el contexto los relaciona con una especial mención de Horacio a esos dioses como la que configura el Carmen Saeculare.

En efecto, el soneto XX («Almo divino sol, que en refulgente...») está puesto en relación con el Canto Secular ya por Menéndez Pelayo ${ }^{32}$. Las alabanzas que en el soneto dirige al sol y la luna, con sus diferentes advocaciones y epítetos clásicos, son exactos a los de Horacio en su extensa oda. Un detalle de interpretación nos ayuda a refrendar la atribución: en el v. 5 invoca la «pura i cándida Ilitia», sobre lo que B. López anota a pie (p. 161): "Genio femenino de los alumbramientos, hijo de Zeus y Hera; entre sus hermanos se cuenta Hefesto, dios del fuego. Pero resulta más convincente pensar con Chiappini (pág. 437) que aquí el poeta identifica a llitia con Diana (la luna) hermana de Apolo (el sol)». Ciertamente la relación con Diana parece clara, aunque no sea absolutamente necesaria la identificación plena (cuestión en la que hay que ser cauteloso y revisar a fondo las fuentes clásicas para Ilitía, tarea no sencilla que no vamos a abordar ahora), y es fácil darle una sólida base con recurrir al modelo: en el verso 14 del Carmen Saeculare aparece Ilitía, justo tras la advocación a Apolo y en relación con otros «genios» natalicios:

rite maturos aparire partus

lenis, Ilithyia, tuere matres,

siue tu Lucina probas uocari

seu Genitalis.

Este simple detalle nos verifica ya la relación con el inconmensurable Canto Secular.

\section{Motivos marinos horacianos}

El mar ocupa un lugar destacado en la temática de Rioja. Así lo destaca B. López Bueno en las pp. 61-63 de su edición. Pero muchos de sus motivos están ya en la tradición horaciana plenamente desarrollados. Desde luego el motivo marino más famoso de Horacio es el de la nauis que aparece en I 14,

32 P. 330 de Bib... cit., t. VI. 
célebre poema glosado desde muy antiguo, traducido e imitado por muchos de nuestros clásicos e identificado desde el principio con una alegoría del estado: ésta era apuntada ya por Quintiliano ${ }^{33} \mathrm{y}$, tras discutir sus fuentes griegas, Pasquali ${ }^{34}$ concluye que, frente a otras interpretaciones «è pure preferibile l'antica interpretazione allegorica» ${ }^{35}$. Igualmente lo refrendan muchos autores, como Virgilio Cremona ${ }^{36}$, y veremos cómo la orientación política triunfa en la tradición, en Rioja desde luego.

Pero se puede advertir cómo la capacidad de sugerencia de la imagen es enorme, y puede dar lugar a muy diferentes interpretaciones ${ }^{37}$; entre ellas se ha venido a identificar como una imagen tormentosa de las vicisitudes amorosas del poeta ${ }^{38}$.

Así, aparece en frecuente contaminación con otras odas horacianas de tema marino como la II 16 y varios pasajes de la II 10, en Fernando de Herrera, naufragado en los mares de su amor por la condesa de Gelves: canc. III de Versos II; El. I de Versos III; El. III, 256-58 y son LXX de Algunas obras..., por recordar sólo algunos lugares.

Este uso amoroso del tópico lo emplea Rioja en el ya mencionado poema a Lice, el son. LVI:

Hiere con saña el mar i con porfía

la seca arena, a su crueldad desnuda,

i l'agua, siempre en el herir más cruda,

temblor embuelto en su furor l'envía.

Pero nunca a sus ímpetus desvía

la frente el polvo numeroso, o duda

permanecer en ser constancia muda,

por más que oculto se repare el día.

33 Inst. Orat. VIII 6, 44,

34 G. PASQUali, Orazio lirico, Florencia, 1966; destaca sobre todo la fuente de Alceo (frs. 6 y 326 L-P.) y de otros líricos griegos.

35 Ibid. p. 20.

36 En el capto. II, «Il superamento del fastidium rei publicae» de su libro La poesia civile di Orazio, Milán 1982, pp. 67 ss.

37 Como ejemplo peregrino podríamos recordar incluso el simbolismo sexual que creía ver RICHARD MIRADEO: «My own conviction is that it connots the phallus, with the poem as a whole representing a serio-comic Horatian expostulation to that amorously impulsive side of his nature that we have come to know so well», The Golden Plectrum. Sexual Symbolism in Horace's Odes, Amsterdam, 1982.

38 La facilidad de interpretación amorosa del símil en Horacio la defiende N.K. ZUMWALT, «Horace's navis of love poetry», The Classical World LXXI, 1977, pp. 249-254. 
Solo ofendiendo, el ponto entre sus iras suspira en el silencio de l'arena, como si alguna vez fuera ofendido.

Tal, Lice, entre las lágrimas suspiras, i el repetido aliento en mí mal suena, mudo yo a tus injurias i herido.

Se trata, como vemos, del uso particular de un motivo horaciano codificado, sin referentes verbales directos ni nada que denuncie una presencia inapelable del modelo, sino simplemente el recurso a un tema que tiene en Horacio su raíz pero ya «de dominio público». La fuerza expresiva de la imagen se concreta, como es propio del lirismo, en la situación personal del poeta, desvelada en el último terceto con el horaciano vocativo Lice va comentado.

Pero, como decíamos, el motivo marino en Rioja prefiere la tradicional intención política, desviada de la nave del estado a la ambición personal. En este sentido se transfiere a la esfera económica, social o estrictamente política, siempre características del hombre que vive el turbulento mundo barroco.

Así aparece en los sonetos XI, XVII y XVIII. Recordemos como ejemplo el XI:

Claro i tranquilo el mar me conduzía a que sulcara su profundo seno, $i$ apena entre, cuando el color sereno huyo, de Bóreas con la saña fría.

Crespos montes de umor al cielo vía subir, i el mar, d'oscura sombra lleno, cambiar varios semblantes, $i$ el terreno assiento entre las olas parecía.

Entonce, ¡ai!, ô mesquino!, un mortal yelo me cubrra, i el güeco leño roto luchava con las aguas fatigado.

En tanto afán, con voz ya incierta, al cielo moví a piedad; libróme, i hize voto de fiar nunca en ponto sossegado.

El terceto final, con el voto al cielo nos recuerda otra imagen marina también típica de Horacio, que es la que contienen los últimos versos de la oda I 5: 
...me tabula sacer

uotiua paries indicat unida

suspendisse potenti

uestimenta maris deo.

Como en otros casos, es de larga tradición, imitada por Garcilaso en pasaje detectado por Herrera y luego imitado por él. En Rioja lo encontramos en el soneto XXXIV, detectado ya por Chiappini (p. 468 de su ed, cit.):

Vime del Adria en la sobervia fiera, el vigor $i$ el aliento desmayado, juego ya de las olas, i arrojado soi, naúfrago, despojo en la ribera.

Don Juan, ¿en mi fortuna quién creyera tan súbita piedad de ponto airado? Temíme entre sus olas sepultado, i salvo a un tiempo me contemplo fuera.

Colgaré úmida veste en sacro templo, al eterno i común Señor por voto: será acaso escarmiento al atrevido;

mas, ¿cómo a mí, si ai lisongero olvido, i no asiste en imagen para ejemplo viento i turbado mar i pino roto?

La relación con Horacio es indudable, refrendada por los mismos términos que hemos destacado en cursiva (el cambio del maris deo por el Señor es frecuente en la moral de la época). Pero al contrario de lo que comentábamos al principio sobre adaptar el tema político a lo amoroso, en este poema ocurre al revés. El motivo del exvoto está en una oda erótica y aquí Rioja lo adapta a la ambición personal.

Pero la imagen de la nave como ambición no es sólo entendida como personal, y así la aplica como ejemplo para advertir a sus «amigos». En dos casos aparece en poemas dirigidos al conde-duque de Olivares, cuando aún era don Gaspar de Guzmán, que ya debía apuntar una desmesurada voracidad política. Digamos de paso que lo advoca con el pseudónimo de «Manlio», cónsul citado por Horacio (III 21, 1), y muy a la manera en que ésta advierte y amonesta a sus amigos en sus odas.

Los lugares en cuestión son el soneto XXII y los tercetos del XXVII, donde tras referirse a su situación personal utiliza el símil de la nave: 
Nave que pudo el mar embravecido

firme sufrir, i al viento más airado,

ya vi perder en arenoso assiento;

i el vidrio a luenga edad nunca rendido,

ni del agua i la llama sojusgado,

lo vence i lo consume un blando aliento.

Por último, en el son. LII ocurre al contrario: desarrolla el motivo de la «navis» en los cuartetos y en los tercetos introduce una reflexión moral asaz horaciana:

¡Ô rotos leños i mojado lino, orror a la ambición más lisongera!

¿Qué mal fundado error tu paz primera

en la selva turbo, robusto pino?

I tú, atrevida yerva, que camino

a fábrica naval diste en la fiera

agua, ya por su injuria en la ribera

eres triste escarmiento al peregrino.

¡Ô mil vezes dichoso el que igual cuenta

largas oras en ocio entre sus lares,

superior a vulgares opiniones,

que ni a la suerte invidiará sedienta,

ni, inútil peso, temerá en los mares

escrudiñar sus íntimas regiones!

El desarrollo del motivo marino mezcla tópicos ya vistos con la condena de la navegación, otro motivo clásico ya tópico que Horacio expresa en, por ejemplo, I 3, 9ss. Pero aquí nos interesa cómo deja la última sección del poema para una reflexión moral que nos da paso al tema filosófico.

\section{El tema filosófico-moral}

La filosofía hoarciana es un caso peculiar de síntesis de dos doctrinas contrapuestas, pues a su famosa moral de renunciación y aurea mediocritas, une 
un evidente epicureísmo ${ }^{39}$, que le ha ganado un éxito sin precedentes como modelo de nuestros reflexivos líricos del Siglo de Oro. Como es natural, se destaca más la vena estoica, pero el conjunto de la filosofía horaciana es bien aceptado y adaptado.

La alabanza de la virtud y la templanza en clave horaciana es desarrollada a menudo por Rioja, recurriendo a motivos e imágenes como el árbol que saca fuerzas del mismo hierro que lo corta, que aparece en Horacio ( IV 4, 5760) como una encina, comparada al guerrero:

...duris ut ilex tonso bipennibus

nigrae feraci frondis in Algido, per damna, per caedis, ab ipso ducit opes animumque ferro.

Pasado ya por Fray Luis (XII 31-35):

Bien como la ñudosa carrasca, en alto risco desmochada con hacha poderosa, del ser despedazada del hierro torna rica y esforzada ${ }^{40}$

Lo recoge Rioja codificado en un contexto de exhortación al ánimo y la virtud (son. XXV, 9-11):

Mira cómo del hierro i la herida la mal derecha vid orna su frente con verde veste i con purpúrea gloria.

Pero aparte de detalles de imaginería, el peso de las odas de Horacio impera por su contenido, expresándose en poemas enteros de Rioja teñidos de su doctrina. Así un modelo horaciano fundamental de moralidad es la oda III 3:

39 Cf . N.T. De Witt, «Epicurean doctrine in Horace», CPh 34, 1939, pp. 127-134; K. GANTAR, «Horaz zwischen Akademie und Epikurn, Ziva Antika 22, 1972, pp. 5-24; P. KesSELING, «Carpe diem; Horat. Od. I 11, 8 und Epikur bei Diog. Laert. X 126m, Philologische Woschenschrift 47, 1927, pp. 508-509; J. KROLL, «Horaz' Oden und die Philosophie», Wiener Studien 87, 1915, pp. 223-238: W.D. LEBECK, «Horaz und die Philosophie», ANRW, 1981, II, 31.3, 1987-2.029; O. TESCARI, «La filosofia in Orazion, Conuiuium 8, 1937, pp. 193-206; y, entre nosotros, V. VALCARCEL, «Horacio: Poeta versus Filósofo», EClás 30, 1988, pp. 35-41.

40 Citamos por la ed. de J.F. AlCINA, FRAY LUIS DE LEON. Poesía. Madrid, Cátedra, 1987, p. 138. 
Iustum et tenacem propositi uirum

non ciuium ardor praua iubentium,

non uultus instanti tyranni

mente quatit solida neque Auster,

dux inquieti turbidus Hadriae,

nec fulminantis magna manus louis:

si fractus illabatur orbis,

impauidum ferient ruinae.

Pasado por Herrera en $A l$ varón firme y justo $\left(n^{\circ} 88\right.$ de Poesías varias en la ed. Cuevas), Rioja recuerda la oda en el soneto XLIX de que ya hemos hablado, en el segundo cuarteto a que nos referíamos por su desprecio del vulgo, con eco también del comienzo de III 3:

Emulas, Manlio, son de las divinas

tus acciones; del número embestido

ni passas a sus vozes advertido,

ni a sus injurias aún la frente inclinas...

pero desarrollando otras partes del poema, también de larga tradición, en el primer cuarteto:

¡Cómo a ser inmortal, Manlio, caminas!,

pues cuando el orbe en pieças dividido,

cae con ímpetu orrendo i con rüido, intrepido te hieren sus ruinas.

recogiendo el si fractus illabatur orbis/impauidum ferient ruinae que, curiosamente, también traducía Herrera en las Anotaciones.

Ecos evidentes de toda la oda III 3 ofrece también Rioja en la silva V, $A$ la constancia, dedicada, como las de Horacio, a un amigo, Francisco Pacheco. La imagen del piélago que golpea está ya en el comienzo:

¿Ves cómo las riberas permanecen

firmes, Pacheco, al ponto embravecido?, que aunque al orrendo golpe se estremecen con el temor quizá del gran rüido, después de roto un mar, con igual frente animosas aguardan el siguiente.

Tal juzga mi firmeza... 
Y podemos observar, como se ha señalado en otras ocasiones, la contaminatio de textos horacianos. En efecto, en este contexto de horacianismo, el comienzo de «iVes cómo...?» hace recordar necesariamente el Vides ut...? de la también reflexiva oda I 9.

En esta línea la silva $\mathrm{V}$ presenta también influencias de II 3 Aequam memento, señaladas por B. López en su ed., así como de III 24, 31-32:

Virtutem incolumen odimus, sublatam ex oculis quaerimus inuidi,

en los vv. 38-43:

Presente la virtud, no resplandece
como deve, con onra no manchada,
antes es perseguida i denostada;
mas descúbrese ausente, i aparece
el puro lastre suyo,
y entonce ${ }^{41}$ aun del contrario es desseada.

Otro poema de Rioja con tema moral horaciano de incuestionable relación es la silva IV, A don Francisco de Villalón, que es imitación de la oda II 16 Otium dius rogat in patenti. Ya desde su comienzo, «Ocio a los dioses pide», parece bastante literal. Sin embargo el desarrollo del poema es más libre, pero no tanto como dice Chiappini (p. 461): «la silva trae dal Venosino solo alcuni materiali da inserire sapientemente in un contesto dal tono completamente diverso". La moral horaciana es omnipresente $y$, frente a escasos ecos textuales evidentes (como «Egeo» v. 4=Aegaeo, v.2), son abundantes las expresiones parafrásticas de los motivos de Horacio: así los vv. 5-10 responden a los 5-8 de Horacio; el 16 reproduce $7-8 ; 28-30$ son paráfrasis de 8-12, etc.

Ciertamente, y como antes expresábamos, no nos interesa tanto la diferencia, que obedece al gusto y concepto de la imitación en la época, con su prurito de variación, cuanto la relación, que es incuestionable.

Y junto a la renunciación y la virtud, aparece el otro gran tópico horaciano: el archifamoso carpe diem de la oda I 11, puesto curiosamente en relación con las reflexiones que venimos estudiando, ya que la exhortación a la virtud

41 La ed. de B. LOPEZ BUENO trae «entonces» que hace imposible la métrica. No sabemos si será errata o lección de su texto base, pero parece necesaria la corrección *entonce» atestiguada además por su uso en Rioja en otros lugares, metri causa, cono en son. XI, 9, p. e., en alternancia con «entonces». 
parte del reconocimiento de la contingencia, consciencia que puede operar en el sentido contrario: el epicúreo y vitalista disfrute del poco tiempo que se nos concede. Así, el soneto XXX:

Fabio, miraste i luego a la amorosa hacha ardiste; no acuso la presteza, qu'es nueva admiración l'alma belleza de la en ti dulcemente poderosa.

Los cándidos jazmines $\mathrm{i}$ la rosa qu'en su frente esparzió naturaleza, ¿quién vio jamás?, ¿i quién l'alta viveza i llamas de sus luzes gloriosa?

Tú, pues, prudente, qu'el correr no inoras del puro sol a oscura noche fría, ardes en viendo lumbre soberana.

Arde, que huyen las veloces oras, i no se sabe si al presente dia, Fabio, podrá añadirse el de mañana.

El final de la I 11 es evidente, ...fugerit inuida/aetas; carpe diem, quam minimum credula postero. La fórmula que sigue al carpe diem, esa incertidumbre frente al día siguiente, es especialmente querida de Rioja, que la expresa también en su silva VI, vv. 86-87:

que no sabes si al día claro i puro otro podrás contar ledo i seguro.

El tópico de la fugacidad del tiempo y la exhortación al goce se expresa también con otro tópico clásico como es el famoso collige, Virgo, rosas, que contiene el De rosis nascentibus atribuído a Ausonio ${ }^{42}$; pero aparece a menudo en contextos horacianos, combinado con el carpe diem y con la oda IV 10, donde se trata de la belleza de la dama y su caducidad; esta oda goza también de gran éxito, $y$ fue hermosamente traducida, en un soneto, por Fernando de Herrera ${ }^{43}$. Alli

42 Cf. Blanca González Escandón, Los temas del «carpe diem* y la brevedad de la rosa en la poesía española, Barcelona, 1938.

43 Cf. I. Osuna, sla oda IV 10 de Horacio traducida por FERNANDO DE HERRERA» Archivo Hispalense $n^{\circ} 228,1992$, pp. 83-93. 
el soneto se impregna de tópicos petrarquistas, en un curioso maremagnum de fuentes, que llega así al soneto XXXVII de Rioja:

Sin razón contra el cielo, Aglaya mía, mueves airada el labio, porque a dado veloz fin a tu lustre $i$ al dorado pelo qu'en tu alva frente reluzía.

Si la flor que aparece al nuevo día, el crespo seno en púrpura bañado, con color se ve en tierra desmayado antes que el mismo mar tuerça la vía.

Porqu'el fuego i la nieve dulcemente en tu rostro mesclados, ¿qué otra cosa son que una breve flor? Templa la saña;

que la fatal disposición no engaña, si a quien alta belleza floreciente, la edad le da de la purpúrea rosa.

La misma suma de motivos aparece en los sonetos XIV y XV, introduciendo así los motivos florales tan del gusto de Rioja.

\section{Las flores y la naturaleza}

Las silvas y sonetos de Rioja son un jardín donde crecen las más variadas flores, que podíamos decir son su motivo favorito ${ }^{44}$. Aparte de sus silvas $A$ la rosa, Al clavel, Al jazmín... que dan lugar a distintas reflexiones, recordemos el soneto IX, donde la hoja caduca presenta igual función horaciana:

Ya la hoja que verde ornó la frente desta selva, don Juan, en el verano,

44 Cf. J.M. Cossio, «Cuatro poetas ante las flores. Rioja, Polo de Medina, C. Coronado y Amós de Escalante», Finisterre 42, 1948 y P. HenríqueZ UREÑA, «Rioja y el sentimiento de las flores», En Plenitud de España. Estudios de la historia de la cultura, Buenos Aires, Losada, 1945. 
tiende amarilla por el suelo cano

fuerça de elado espíritu ardiente;

i la ova que en agua vi pendiente de un güeco risco con verdor loçano, mustio ya i sin color, despojo vano, Betis esplaya con mayor corriente.

I yo assí bien no desigual mudança siento en $\mathrm{mi} \mathrm{mal,} \mathrm{que} \mathrm{ya} \mathrm{mi} \mathrm{ardor} \mathrm{intenso}$ cambia el yelo en ceniza vana y fría.

¿Quién esperó igual bien? ¡Ô grata usança del tiempo: que fallece a par del día si un hermoso verdor, un fuego imenso!

El procedimiento es tan típico horaciano como lo describe V. Cristóbal ${ }^{45}$, cuando dice que a la naturaleza «suele contemplársela en el momento pasajero de la estación, cuando cambia de rostro, con la intuición de su constante mutabilidad. [...] Esta periódica renovación le sirve al poeta para crear un contraste con la irrevocable finitud del ser humano". Esto ocurre también en Rioja, ya en el comienzo de la silva VI cuyo final horaciano dejamos sentado (con la imitación del quam minimum credula postero). Comienza la silva $A l$ verano con la llegada de éste:

Fonseca, ya las oras

del ivierno aterido, aunque tarde, se fueron

i su vez agradable permitieron

el zéfiro florido.

Ya el verano risueño nos descubre su frente de rosas i de púrpura ceñida...

que recuerda especialmente los comienzos de la oda IV 7 (Diffugere niues, redeunt iam gramina campis/arboribusque comae) y I 4 (Soluitur acris hiems...) ${ }^{46}$.

45 Horacio. Epodos y odas. Madrid, Alianza, 1985, pp. 21-29.

46 Cf. A.J. WoOdMaN, «Horace's Odes Diffugere niues and Soluitur acris hiems», Latomus 31, 1972, pp. 752-758; P., DEFOURNY, «Le printemps dans l'ode à Sestius (I 4)», Les Etudes Classiques 1946, pp. 174-194. 
La contemplación de la naturaleza cambiante y su parangón con la intimidad del poeta se lleva también al terrreno amoroso en los sonetos III y XVI. En el XXI, más que la llegada del verano, se insiste en el incesante cambio, comenzando por el estío, vuelta al invierno y otra vez la llegada del verano, mezclando tópicos del Diffugere como la crecida del río y su vuelta al cauce (et decrescentia ripas/flumina pratereunt, vv. 3-4), con otros como el comienzo de I 9, Vides ut alta stet niue candidum que ya señalábamos imitado al comienzo de la silva V. Copiamos el soneto XXI como ejemplo más conspicuo de esta utilización (ya se ha señalado la callida iunctura de su primer cuarteto):
Este sediento campo, que abundoso de roxa mies contemplo en el estío, vi cubierto de umor luziente y frío en el órrido ivierno i proceloso.
I este de luengos cuernos caudaloso Betis, correr de nuevo orgullo y brio vi ya, i descrece $i$ con angosto ro entra en el ancho piélago espumoso.
Mas nunca, ¡ai, ô dolor!, mi incendio veo menguarme un poco, o robe soplo elado onra a la selva o tibio la corone.
I el hado, aun en tan grave mal, dispone que muera en mi impetuoso devaneo en lágrimas $i$ en fuego desatado.

Lo propio del lirismo, la transferencia a la esfera personal de la contemplación de un hecho natural, y su expresión de manera que lo personal es universal y compartido por el lector, se plasma de esta manera tan horaciana y tan nuestra a la vez, en un pensamiento existencial que nunca pasará de moda.

\section{CONCLUSIONES}

Hemos visto, pues, unos cuantos casos de horacianismo en Rioja a diferentes niveles, que ni mucho menos agotan el campo de la imitación de Horacio en nuestro poeta. Son sólo ejemplos selectos que reivindican la relación de 
ambos autores a un nivel más profundo del que suele señalarse, y que van desde la adopción de rasgos formales, pasando por ecos verbales e imitación directa, hasta la recreación de motivos concretos y de los grandes temas que el venusino formuló de manera insuperable. Insistimos pues, una vez más, en el horacianismo de la escuela sevillana que no tiene por qué seguir las directrices de otros grupos poéticos para imitar a Horacio.

Pongamos todo esto, para acabar, en un soneto, la estrofa favorita de Rioja:

Las formas que en la lírica romana Horacio construyo en su monumento, tomaron en España nuevo aliento llegando hasta la escuela sevillana,

Dichoso aquel poeta que se afana por dar a su creación el ornamento de los antiguos, mas con tanto tiento que no incurre en la copia burda y vana.

Así tomó Francisco de Rioja los temas y motivos horacianos, y el libro de sus versos se deshoja dejando oda tras oda entre sus manos. Con ellas ha encontrado cierta guía que alumbra, verso a verso, su poesía. 